\title{
Analisis Loyalitas Pelanggan Industri Jasa Pengiriman Menggunakan Structural Equation Modeling
}

\author{
Sarika Zuhri ${ }^{1}$, Andriansyah ${ }^{2}$, Didi Asmadi ${ }^{3}$, Siti Khajar $^{4}$
}

\begin{abstract}
Customer loyalty is important for both product and service industries. A loyal customer keeps using the company's product and services. For a shipping service company, retaining existing customers in order to remain faithful will certainly be very crucial. This study was to determine relationship between variables affecting customer loyalty at PT. Pos Indonesia-Banda Aceh, a shipping service industry. The research used Structural Equation Modeling (SEM) and with samples of 153 questionnaires obtained through a non-probability sampling technique. By using AMOS software, it can be concluded that the perceived quality does affect customer satisfaction, perceived value has influence on the customer satisfaction, the customer satisfaction is influential to trust and the trust itself has positive influence on customer loyalty.
\end{abstract}

Keywords. customer satisfaction,costumer loyalty, shipping service industry, SEM.

\begin{abstract}
Abstrak.Loyalitas pelanggan merupakan suatu hal yang sangat penting dalam sebuah industri baik itu produk maupun jasa. Jika pelanggan sudal loyal pada perusahaan atau organisasi tertentu maka pelanggan akan terus menggunakan produk atau jasa dari perusahaan tersebut. Mempertahankan pelanggan yang sudah ada agar tetap setia tentunya akan menjadi penting sekali bagi pelaku jasa pengiriman. Tujuan dari penelitian ini untuk mengetahui hubungan antar variabel yang mempengaruhi loyalitas pelanggan pada industri jasa pengiriman (kurir) PT. Pos Indonesia-Banda Aceh.Penelitian ini menggunakan Structural Equation Modelling (SEM) dan sampel yang berhasil dikumpulkan sekitar 153 kuesioner melalui teknik non probability sampling. Dengan menggunakan software AMOS, dapat disimpulkan bahwa perceived quality berpengaruh terhadap kepuasan pelanggan, perceived value berpengaruh terhadap kepuasan pelanggan, kepuasan pelanggan berpengaruh terhadap kepercayaan dan kepercayaan berpengaruh terhadap loyalitas pelanggan.
\end{abstract}

Kata Kunci.Kepuasan pelanggan, Loyalitas pelanggan, industri jasa pengiriman, SEM

\section{Pendahuluan}

Loyalitas (customer loyalty) merupakan suatu hal yang sangat penting bagi seluruh industri baik

\footnotetext{
Sarika Zuhri, Prodi Teknik Industri, Jurusan Teknik Mesin dan Industri, Fakultas Teknik, Universitas Syiah Kuala, Banda Aceh (email: sarika89zuhri@gmail.com)

2 Andriansyah, Prodi Teknik Industri, Jurusan Teknik Mesin dan Industri, Fakultas Teknik, Universitas Syiah Kuala, Banda Aceh

${ }^{2}$ Didi Asmadi, Prodi Teknik Industri, Jurusan Teknik Mesin dan Industri, Fakultas Teknik, Universitas Syiah Kuala, Banda Aceh

${ }^{2}$ Siti Khajar, Prodi Teknik Industri, Jurusan Teknik Mesin dan Industri, Fakultas Teknik, Universitas Syiah Kuala, Banda Aceh
}

Diajukan: 01-09-2016 Disetujui: 10-12-2016 itu produk maupun jasa, ketika pelanggan sudah menjadi loyal untuk selalu menggunakan produk atau jasa dari suatu perusahaan tertentu, maka dapat dikatakan bahwa perusahaan tersebut sudah berhasil memberikan kepuasan kepada pelanggannya karena pada dasarnya kepuasan pelanggan merupakan salah satu faktor penting yang bisa membuat pelanggan menjadi loyal (Oliver, 1999). Loyalitas pelanggan datang pada saat pelanggan merasa puas setelah mengggunakan jasa atau produk dari perusahaan tertentu. Pelanggan yang loyal akan selalu menggunakan jasa atau produk tersebut. Hal ini sangat menguntungkan bagi perusahaan, karena pelanggan yang loyal tentunya akan memberikan kontribusi sangat positif bagi keuntungan perusahaan.

Kepuasan pelanggan harus diciptakan oleh perusahaan, agar bisa mendapatkan pelanggan yang loyal (Chan, 2003). Salah satu unsur penting dalam kepuasan pelanggan adalah 
kualitas. Kepuasan pelanggan akan semakin meningkat seiring dengan semakin tingginya kualitas yang diberikan oleh perusahaan. Kualitas layanan yang diciptakan tidak bisa diukur dari sudut pandang perusahaan, namun harus dari sudut pandang pelanggan (perceived quality) (Kotler\& Armstrong, 2001).

Tjiptono (2002) mengungkapkan bahwa kualitas jasa yang baik memberikan dorongan kepada pelanggan untuk menjalin hubungan yang kuat dengan perusahaan. Pelanggan yang terbaik adalah pelanggan yang setia. Oleh karena itu, perusahaan harus dapat mengidentifikasikan, mempertahankan dan memperkuat loyalitas. Namun, dewasa ini tidak hanya kualitas yang dibutuhkan untuk dapat mempertahankan pelanggan, perusahaan harus lebih kreatif untuk memberikan nilai tambah (added value) pada jasa atau produk yang ditawarkannya (Kotler, 1997).

Saat ini bisnis jasa pengiriman barang di Indonesia berkembang cukup pesat. Hal ini ditandai dari munculnya sejumlah perusahaan jasa pengiriman yang bergerak dalam bidang industri jasa pengiriman. Adanya perkembangan permintaan pasar terhadap permintaan jasa pengiriman, menjadi latar belakang semakin banyaknya pelaku usaha yang berkiprah dalam sektor jasa pengiriman.

PT. Pos Indonesia merupakan Badan Usaha Milik Negara (BUMN) yang bergerak dalam kegiatan pelayanan lalu lintas informasi, uang dan barang. PT. Pos Indonesia menyediakan jasa dengan banyak produk seperti pengiriman paket, setelah disahkannya Undang-Undang No. 38 tahun 2009 tentang penguasaan pasar pengiriman surat dan paket dengan berat dibawah 2000 gram yang kini dapat dijalankan oleh perusahaan milik negara maupun swasta. Hal ini mengakibatkan sebagian besar pangsa pasar jasa pengiriman paket dikuasai oleh perusahaan swasta, seperti JNE, TIKI, Indah Cargo dan jasa pengiriman barang lainnya. PT. Pos Indonesia dituntut untuk terus meningkatkan kualitas pelayanannya, agar pelanggan menjadi loyal dan dapat menghadapi kompetitor yang bergerak dalam bidang industri jasa pengiriman.

Jasa pengiriman barang PT. Pos Indonesia Cabang Banda Aceh mengalami perubahan menurun yang disebabkan oleh adanya faktor persaingan yang berasal dari perusahaan pengiriman barang, selain dari PT. Pos Indonesia cabang Banda Aceh. Persaingan ini diduga dengan adanya pernyataan masyarakat yang lebih mengunggulkan perusahaan lain dibandingkan PT. Pos Indonesia Cabang Banda Aceh, sehingga memiliki brand image yang negatif di masyarakat seperti barang yang hilang, rusak, ataupun tidak sampai ke tempat tujuan, dengan adanya persaingan tersebut membuat pelanggan tidak loyal terhadap jasa pengiriman barang di PT. Pos Indonesia Cabang Banda Aceh, serta salah satu penyebab ketidakpuasan masyarakat lainnya adalah kurang maksimalnya kualitas layanan, seperti perhatian dalam mempertahankan kualitas layanan, keluhan pelanggan, keterlambatan pengiriman, serta kurangnya pihak manajemen dalam mengolola usahanya dengan baik.

Banyak penelitian terdahulu yang telah melakukan kajian mengenai loyalitas pelanggan jasa pengiriman. Susetiyana (2009) meneliti faktor-faktor yang mempengaruhi loyalitas pelanggan pada industri airfreight forwarder, dengan menggunakan structural equation modelling (SEM). Hasil penelitian menunjukkan bahwa perceived value, perceived quality, costumer satisfaction, trust, customer complaint, dan image memiliki pengaruh terhadap loyalitas pelanggan. Suharto (2012) mengungkapkan variabel yang paling dominan mempengaruhi loyalitas pelanggan adalah kualitas pelayanan dan kepercayaan di PT. Pos Indonesia Cabang Malang dengan menggunakan structural equation modelling (SEM). Sedangkan Kusuma (2014) meneliti tentang pengaruh logistic service quality terhadap satisfaction dan loyalty dengan dimensidimensi logistic service quality yang dikemukakan oleh Huang, dkk. (2009) pada PT. JNE menggunakan structural equation modelling (SEM). Hasil penelitian menunjukkan adanya pengaruh logistic service quality terhadap satisfaction, logistic service quality terhadap loyalty, dan satisfaction terhadap loyalty.

Oleh sebab itu, penelitian ini akan mencoba menganalisis loyalitas pelanggan pada industri jasa pengiriman (Kurir) PT. Pos Indonesia Cabang Banda Aceh untuk mengetahui hubungan antar variabel yang mempengaruhi loyalitas pelanggan, dengan menggunakan structural equation modelling (SEM). Hasil penelitian ini diharapkan dapat menjadi rekomendasi untuk meningkatkan loyalitas pelanggan. 


\section{Metode PENELITIAN}

Lokasi penelitian dilakukan di PT. Pos Indonesia Cabang Banda Aceh (selanjutnya disebut PICBA) yang berkedudukan di Jalan Teuku Amir Hamzah Bendahara, No. 33, Kuta Alam, Banda Aceh, Nanggroe Aceh Darussalam, Indonesia. Penelitian ini dilakukan selama sekitar 2 bulan untuk survei dan pengumpulan data.

Subjek penelitian atau responden adalah pihak-pihak yang dijadikan sampel dalam penelitian. Objek padapenelitian ini adalah pelanggan yang menggunakan PICBA yang bertujuan untuk melakukan transaksi pengiriman di PICBA. Penelitian ini dilakukan dengan waktu \pm 2 bulan yaitu terhitung dari bulan AgustusSeptember 2015. Tabel 1 menunjukkan jumlah pengiriman PICBA selama tahun 2013-2015.

Tabel 1. Jumlah pengiriman PICBA selama tahun 2013-2015

\begin{tabular}{rrrr}
\hline Tahun & $\begin{array}{l}\text { Jumlah } \\
\text { Tunai }\end{array}$ & \multicolumn{1}{l}{$\begin{array}{l}\text { Jumlah } \\
\text { Kredit }\end{array}$} & \multicolumn{1}{c}{ Jumlah } \\
\hline $\mathbf{2 0 1 3}$ & 265.355 & 37.765 & 303.120 \\
$\mathbf{2 0 1 4}$ & 212.342 & 75.114 & 286.456 \\
$\mathbf{2 0 1 5}$ & 54.877 & 25.144 & 80.021 \\
& & Total & 669.597 \\
\hline
\end{tabular}

Sumber : PICBA, 2015

Berdasarkan data jumlah pengiriman PICBA dapat dijelaskan bahwa selama periode 2013 hingga 2015 jumlah pengiriman mengalami penurunan setiap tahunnya. Hal ini mengindifikasikan bahwa dengan terjadi

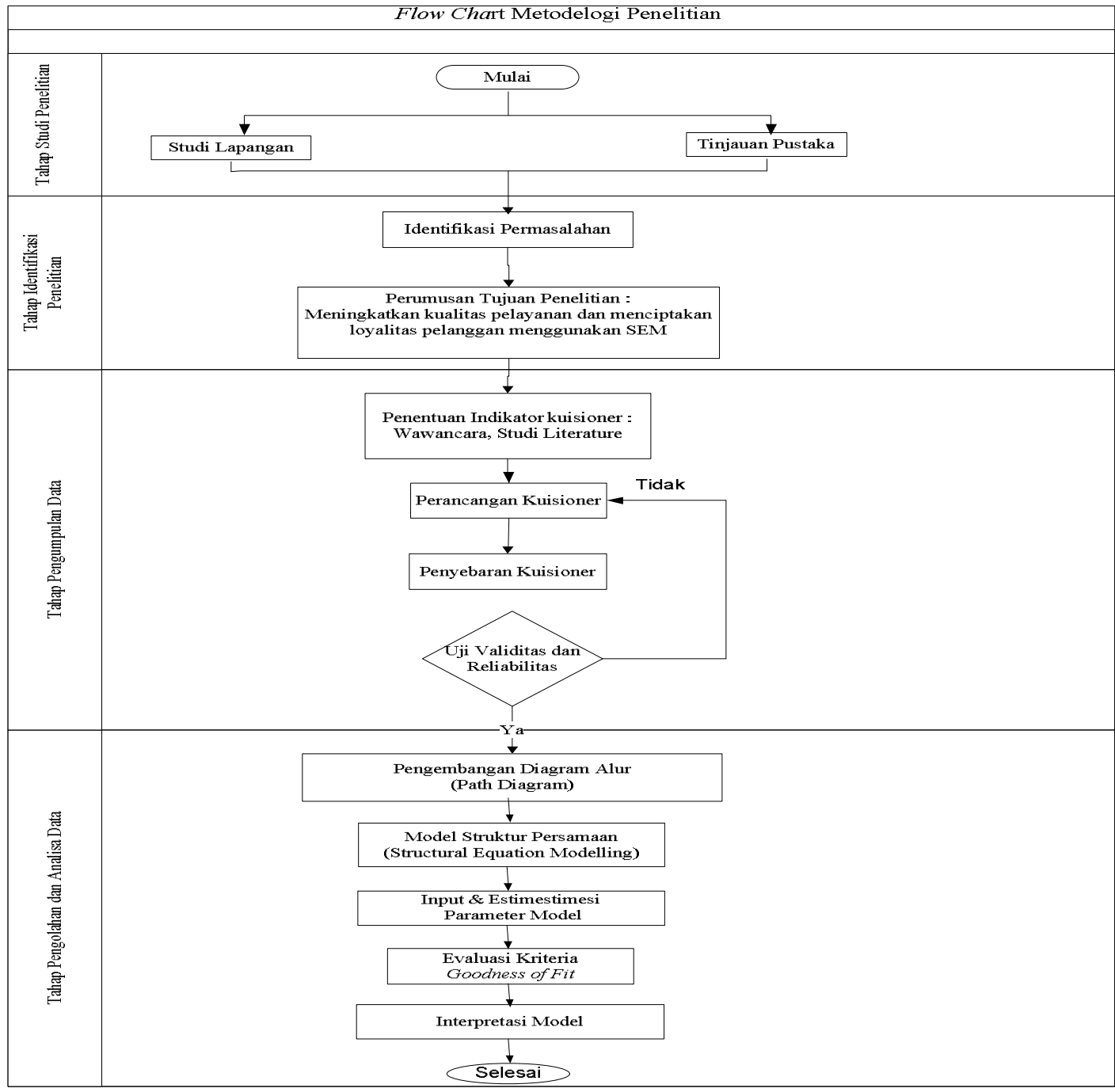

Gambar 1. Diagram metodologi penelitian 
penurunan jumlah pengiriman tersebut menunjukkan loyalitas pelanggan dalam mengunakan jasa PICBA mengalami penurunan.

Artikel ini membahas analisis loyalitas pelanggan pada industri jasa pengiriman dengan menggunakan structural equation modeling (SEM) dengan studi kasus pada PICBA. Pengambilan sampel digunakan teknik non probability sampling dan sampel yang diambil bersifat purposive sampling.

Pada pengumpulan data penelitian ini dilakukan dengan menyebarkan kuesioner kepada responden yang pernah melakukan pengiriman menggunakan PICBA, melalui jurnal-jurnal ilmiah dan buku serta memanfaatkan hasil wawancara dengan pihak PICBA dan pelanggan yang mengunakan jasa pengiriman PICBA. Pengumpulan data bertujuan untuk membantu peneliti merancang suatu pengukuran instrument yang baik sehingga dapat menunjukkan karakteristik dan perilaku pelanggan PICBA secara spesifik. Teknik yang digunakan dalam pengumpulan data adalah teknik wawancara dan survei dengan kuesioner. Gambar 1 menunjuk metode penelitian yang dilakukan.

\section{HASIL DAN PEMBAHASAN}

Model konseptual pada penelitian ini dibangun berdasarkan pada literature penelitian terdahulu.Model konseptual penelitian ini dapat dilihat pada gambar 2. Sedangkan pengujian hipotesis yang terbentuk adalah sebagai berikut :

H1: Perceived quality berpengaruh terhadap kepuasan pelanggan.

H2: Perceived value berpengaruh terhadap kepuasan pelanggan

H3: Kepuasan pelanggan berpengaruh terhadap kepercayaan.

H4: Kepuasan pelanggan berpengaruh terhadap loyalitas pelanggan

H5: Kepercayaan berpengaruh terhadap loyalitas pelanggan

H6: Perceived value berpengaruh terhadap loyalitas pelanggan

Subjek penelitian ini adalah pengguna jasa yang melakukan transaksi pengiriman pada PICBA. Teknik pengambilan sampel yang digunakan pada penelitian ini adalah teknik non probability sampling, yaitu teknik pengambilan sampel yang tidak memberikan peluang atau kesempatan yang sama bagi setiap unsur atau anggota populasi untuk dipilih menjadi sampel (Sugiyono, 2013). Sedangkan jenis pengambilan sampling yang digunakan adalah purposive sampling, yaitu teknik pengambilam sampel dengan adanya pertimbangan tertentu, seperti sumber data yang didapatkan harus dari ahli atau

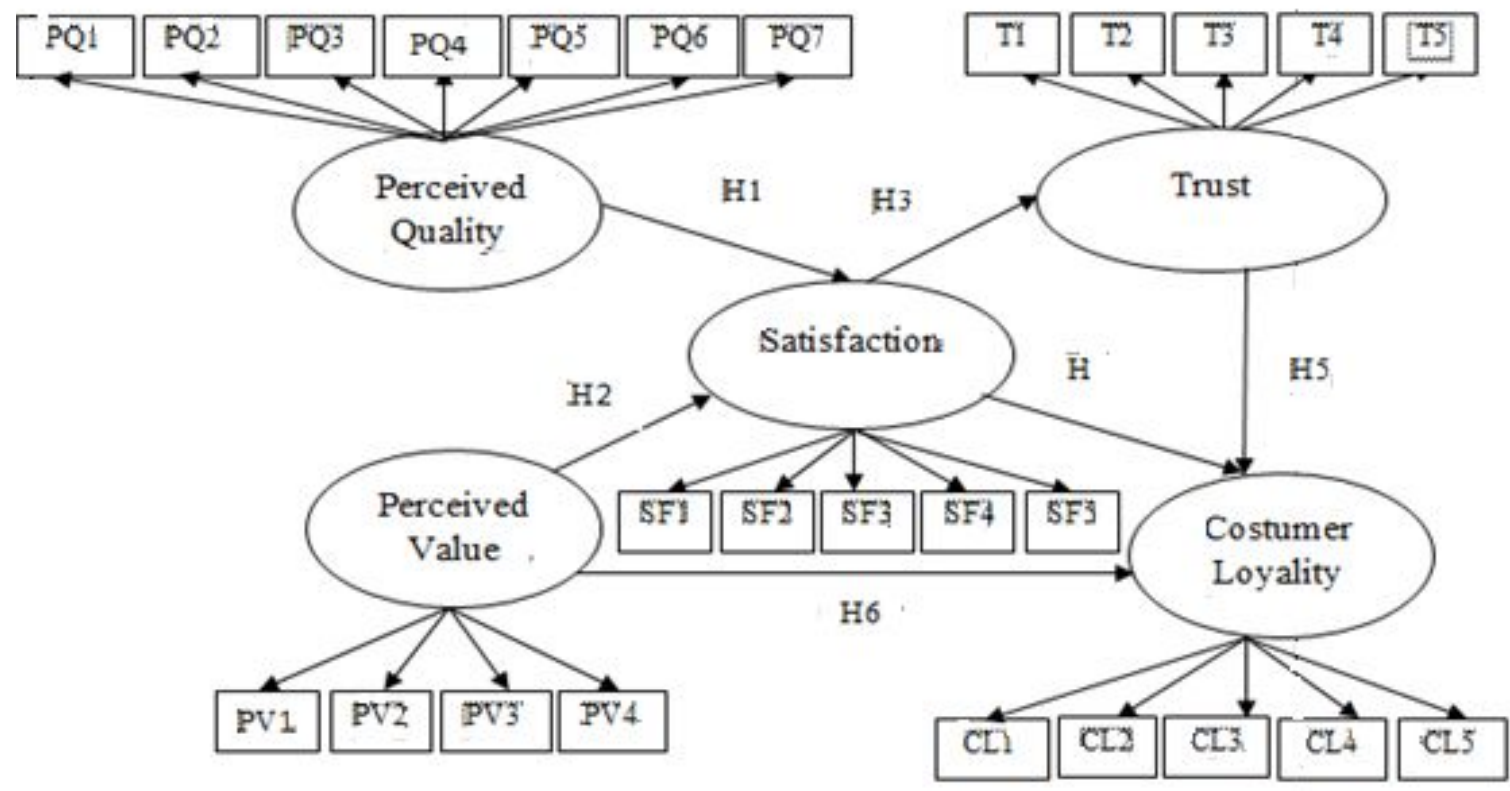

Gambar 2. Model struktural loyalitas pelanggan 
orang yang berwenang (Sugiyono, 2013).

Teknik analisis yang digunakan pada penelitian ini adalah stuctural equation modelling (SEM). Hair dkk. (2006) menyebutkan bahwa model pengukuran sebaiknya menggunakan tiga item yang diukur sebagai indikator dengan sampel antara 100-200 atau 5-10 jumlah kali parameter. Pada penelitian ini, ada 7 indikator untuk perceived quality, 5 indikator untuk kepuasan pelanggan, 4 indikator untuk perceived value, 5 indikator untuk kepercayaan, dan 5 indikator untuk loyalitas pelanggan. Maka total indikator dari lima variabel tersebut berjumlah 26 indikator sehingga jumlah sampel yang dibutuhkan pada penelitian ini paling sedikit 130 responden (26 indikator dikali 5), kemudian peneliti menyebar lagi sebanyak 23 kuesioner, jadi jumlah kuesioner semua adalah 153 .

Pada pengujian ini dilakukan pengujian validitas dan reliabilitas untuk mengetahui kelayakan kuisioner yang dibangun sebelum diberikan kepada responden. Berdasarkan pengolahan data dengan menggunakan bantuan software SPSS dapat disimpulkan bahwa semua atribut pada kuisioner dinyatakan valid dan reliabel. Hal ini dapat dilihat pada $p$ value $>0,05$ berarti valid dan Cronbach's Alpha $>0,6$ berarti reliabel, sehingga dapat disimpulkan bahwa indikator pengukuran untuk semua variabel adalah konsisten. Untuk setiap responden dan jawaban mereka terhadap pernyataan tersebut stabil dari waktu ke waktu, sehingga dapat dikatakan bahwa semua variabel reliabel.

\section{Pengujian Model Struktural}

Model struktural pada penelitian ini dapat dilihat pada Gambar 3. Menurut Santoso (2012) menyatakan bahwa kriteria utama dari pengujian keseluruhan model (overall model fit) adalah pada perhitungan Chi-Square (CMIN). Hasil pengujian tersebut dapat dilihat pada output AMOS seperti pada Tabel 2.

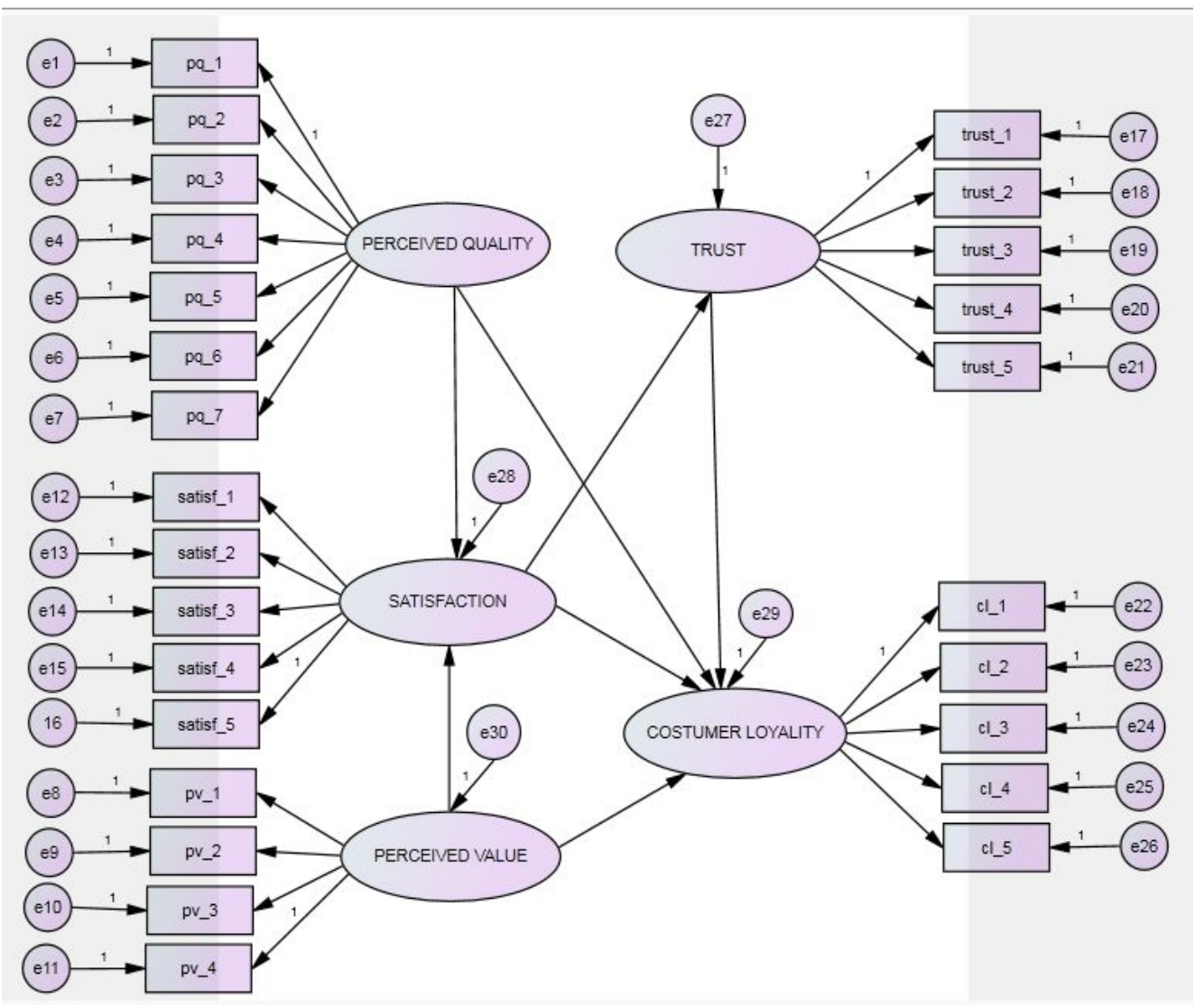

Gambar 3.Output SEM dengan menggunakan AMOS 
Tabel 2. Hasil pengujian model

\begin{tabular}{ccc}
\hline $\begin{array}{c}\text { Testing } \\
\text { fit }\end{array}$ & $\begin{array}{c}\text { Hasil uji } \\
\text { model }\end{array}$ & Tingkat kecocokan yang bisa diterima \\
\hline $\begin{array}{c}\text { Absolute fit indices } \\
\text { CMIN }\end{array}$ 698,998 & $\begin{array}{c}\text { CMIN independence model }<\text { CMIN } \\
\text { default model }<\text { CMIN saturated model }\end{array}$ \\
& & \\
Incremental fit indices & Nilai berkisar $0-1$; mendekati 1 \\
NFI & 0,750 & semakin baik \\
RFI & 0,701 & \\
IFI & 0,838 & \\
TLI & 0,802 & \\
CFI & 0,834 & \\
& & \\
Parsimony fit indices & Nilai berkisar $0-1$ \\
PNFI & 0,626 & Nilai berkisar $0-1$ \\
PCFI & 0,696 & \\
\hline
\end{tabular}

\section{Analisis Hubungan Antar Konstruk}

Untuk mengetahui nilai hubungan antar konstruk dapat dilihat berdasarkan nilai probability $(\mathrm{P})$ pada output AMOS seperti yang ditunjukkan pada Gambar 4. Sedangkan dasar dari pengambilan keputusan adalah sebagai berikut:

- Jika $\mathrm{P}>0,05$ maka $\mathrm{H}_{0}$ diterima.

- Jika $\mathrm{P}<0,05$ maka $\mathrm{H}_{0}$ ditolak.

Dari hasil pengujian hipotesis model yang dapat dilihat pada Gambar 5, maka dapat dilihat berdasarkan model yang telah dianalisis dengan menggunakan perangkat lunak AMOS adalah sebagai berikut:

1. Perceived quality (kualitas yang dirasakan terhadap pelayanan) memiliki hubungan yang signifikan terhadap satisfaction (kepuasan pelanggan). Hal ini sesuai dengan teori sebelumnya yang menyatakan bahwa perceived quality memiliki efek positif terhadap satisfaction (kepuasan pelanggan) (Fornell,dkk, 1996). Dalam industri jasa pengiriman kualitas adalah suatu yang dijual kepada pelanggan, sehingga tentu saja kualitas sangat mempengaruhi kepuasan pelanggan. Semakin baik kualitas yang dijual maka semakin besar kepuasan yang diterima. Kualitas peyalanan baik yang ditawarkan oleh PICBA mampu membuat pelanggan merasa percaya dengan bertransaksi menggunakan PICBA.

\begin{tabular}{|c|c|c|c|c|c|c|}
\hline & & Estimate & S.E. & C.R. & $\mathrm{p}$ & Label \\
\hline SATISF & $<-\ldots P Q$ & .272 & .059 & 4.594 & $* * *$ & \\
\hline SATISF & $<$ PV & .667 & .088 & 7.575 & $* * *$ & \\
\hline TRUST & $<$ SATISF & 1.065 & .143 & 7.435 & $* * *$ & \\
\hline $\mathrm{CL}$ & $<\ldots$ PV & .011 & .145 & .079 & .937 & \\
\hline $\mathrm{CL}$ & $<\ldots$ TRUST & .435 & .174 & 2.494 & .013 & \\
\hline $\mathrm{CL}$ & $<$ SATISF & .425 & .284 & 1.493 & .135 & \\
\hline
\end{tabular}

Gambar 4. Output SEM menggunakan AMOS

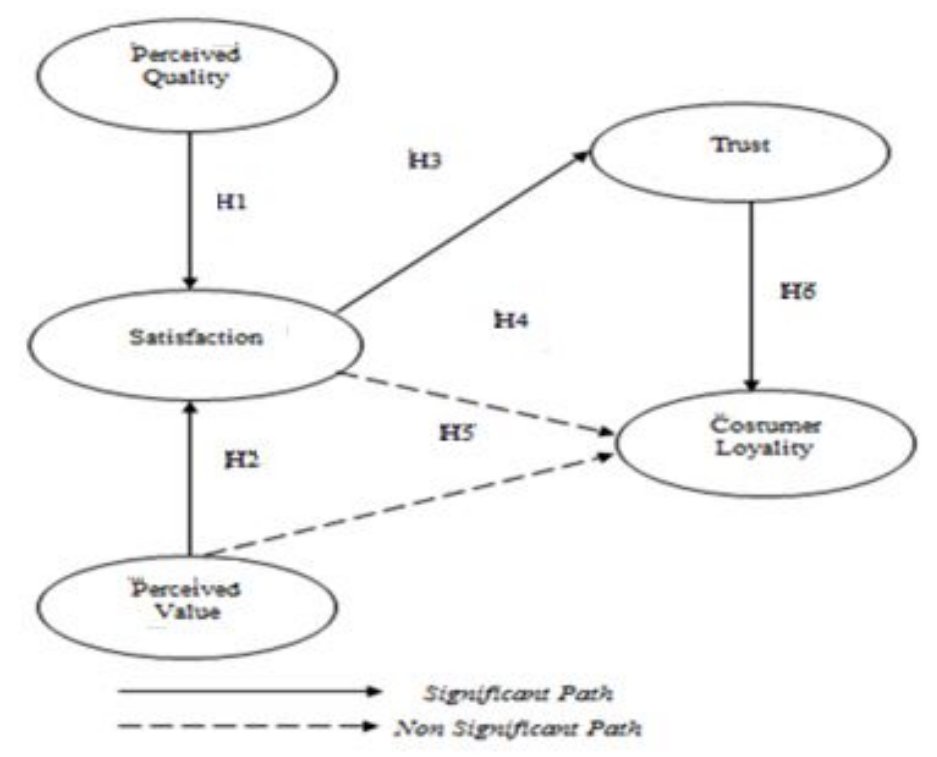

Gambar 5. Model penelitian 
2. Perceived value (nilai yang dirasakan pelanggan terhadap pelayanan) memiliki hubungan yang signifikan terhadap satisfaction (kepuasan). Hal ini sesuai dengan teori sebelumnya yang menyatakan bahwa perceived value dan satisfaction memiliki hubungan positif, dan juga perceived value berbanding lurus dengan satisfaction (kepuasan pelanggan), artinya semakin besar perceived value pelanggan maka akan semakin besar satisfaction (kepuasan) (Bojanic dan Forhell, 1996). Sedangkan antara variabel perceived value dengan customer loyalty tidak mengalami hubungan yang signifikan. Hal ini terjadi karena keramahan yang diberiakan karyawan terhadap pelanggan pada saat bertransaksi maupun menanyakan mengenai keluhan pengiriman yang tidak tepat waktu atau barang yang belum diantar kepada penerima. Serta kurang tanggapnya karyawan dalam membantu keluhan pelanggan jika ada kesulitan. Sehingga hal ini tidak dipengaruhi oleh customer loyalty.

3. Satisfaction (kepuasan) memiliki hubungan yang signifikan terhadap trust (kepercayaan). Hal ini sesuai dengan teori sebelumnya yang menyatakan bahwa suatu pelayanan dinilai memuaskan jika pelayanan tersebut dapat memenuhi kebutuhan dan harapan pelanggan (Kotler, 2000). Kepuasan yang dirasakan oleh pelanggan terhadap pelayanan dan harga mempengaruhi pelanggan terhadap PICBA. Hal inilah yang mengakibatkan pelanggan menjadi loyal dengan PICBA dibandingkan dengan jasa pengiriman lain. Sedangkan antara variabel satisfaction dengan costumer loyalty tidak memiliki hubungan yang signifikan. Hal ini terjadi karena kepuasan terhadap informasi yang diberikan tidak sesuai dengan harapan pelanggan dan juga tarif yang ditetapkan dengan waktu pengiriman yang lama. Sehingga hal ini tidak dipengaruhi oleh customer loyalty.

4. Trust (kepercayaan) memiliki hubungan yang signifikan terhadp costumer loyalty (loyalitas pelanggan). Hal ini sesuai dengan teori sebelumnya yang menyatakan bahwa trust memiliki hubungan yang positif terhadap loyalitas pelanggan (Lertwannawit \& Gulid, 2011). Hubungan antara kepercayaan dan loyalitas pelanggan yaitu semakin tinggi kepercayaan pelanggan terhadap suatu produk, maka akan semakin tinggi pula tinggkat kesetiaan pada suatu produk. Hal ini memungkinkan karena pelanggan telah percaya pada kehandalan dan integritas pada PICBA. Dengan demikian untuk dapat meningkatkatn loyalitas perusahaan perlu untuk lebih memperhatikan kebutuhan pelanggan, menjaga kepercayaan pelanggan terhadap PICBA supaya tidak hilang.

\section{SIMPULAN}

Berdasarkan pengumpulan dan pengolahan data serta analisis yang dilakukan, maka dapat diambil kesimpulan bahwa kepuasan pelanggan dipengaruhi oleh variabelperceived quality dan variableperceived value. Adapun loyalitas pelanggan dipengaruhi oleh variabel satisfaction dan variabel trust.

\section{DAFTAR PUSTAKA}

Chan, S. 2003. Relationship Marketing. Jakarta: PT. Gramedia.

Fornell, C. 1996. "A national customer satisfaction barometer: the Swedish experience". Journal of Marketing, Vol. 55 (1), pp. 1-21.

Griffin, Jill. 2003. Customer Loyalty: Menumbuhkan dan Mempertahankan Pelanggan. Jakarta: Airlangga.

Hair, J.F.; Black, W.C.; Babin, B.J. 2006. Multivariate Data Analysis. Fifth Edition. New Jersey. Prentice-Hall International, Inc.

Huang, K.Y.; Kuo, Y.W.; Xu, S.W. 2009. “Applying importance-performance analysis to evaluate logistic service quality for online shopping among retailing delivery". International Journal on Electronic Business Management, Vol. 7 (2), pp. 128 - 136.

Kotler, P.; Amstrong, G. 2001. Prinsip-prinsip Pemasaran (Edisi 8 jilid I). Jakarta: Erlangga.

Kotler, P. 2000. Marketing Management. New Jersey: Prentice Hall Inc.

Kotler, P. 1997. Manajemen Pemasaran Analisis, Perencanaan, Implementasi dan Pengendalian. (Jilid II, Edisi 9). Alih bahasa: A.A. Hermawan. Jakarta: Prehallindo.

Kusuma, D. 2014. "Pengaruhlogistic service quality terhadap satisfaction dan loyalty di PT. TIKI Jalur Nugraha Eka Kurir". Calyptra,Vol. 3(2), pp. 1 - 14.

Lertwannawit, A.; Gulid, N. 2011. "International tourists' service quality perception and behavioural loyalty toward medical tourism in Bangkok metropolitan area". The Journal of Applied Business Research, Vol. 27(6), pp. $1-12$.

Oliver, R. L. 1999. "Cognitive, affective, and attribute bases of the satisfaction response". Journal of Consumer Research, Vol. 20, pp. 418-430. 
Santoso, S. 2012. Analisis SEM menggunakan AMOS. Jakarta: PT Elex Media Komputindo.

Sugiyono. 2013. Metode Penelitian Kuantitatif Kualitatif dan $R \& B$. Bandung: Alfabeta.

Suharto. 2012. "Pengaruh service quality terhadap loyalitas dimediasi customer value dan customer trust". Jurnal Aplikasi Manajemen, Vol. 10 (1), pp. 199 - 215.

Susetiyana, H. 2009. Analisis Loyalitas Pelanggan pada Industri Airfreight Forwarder dengan Menggunakan Structural Equation Modelling (SEM). Jakarta: Universitas Indonesia.

Tjiptono, F. 2002. Strategi Pemasaran. Yogyakarta: Andi Offset. 